\title{
Electric Vehicles Ultrafast EV Charging Station with Integrated Split Battery Energy Storage
}

\author{
Mohamed A. Zakaria and Mostafa S. Hamad \\ Arab Academy for Science Technology \& Maritime Transport (AASTMT), Egypt
}

\begin{abstract}
In 2019 over ninety percent of the world population breath polluted air below WHO standards (State of Global Air 2020, 2020). With the use of fossil fuel being a main contributed in such a formidable fact. Shifting toward a cleaner source of energy became an obligation. In the field of transportation Electric Vehicles (EVs) are a game changer. However, with this new technology new challenges arise; adequate means of charging must be maintained. This paper provides a comprehensive study about EV ultra-fast chargers. While conventional chargers usually charging with a maximum power of $50 \mathrm{KW}$ (Level-3), charge a vehicle in 20 30mins. The adopted 350KW (Level-4) off-board charger is capable of charging a vehicle in less than 10mins. It is connected to MV grid, thus reducing the load on the LV grid. Further, the bidirectional converters utilized enable vehicle to Grid charging "V2G" operations, which with the aid of a robust power management systems, power can be effortlessly regulated to charge EVs whenever required and support the grid at peak times. The charger encompasses 3 converters. First a Cascaded H-bridge converter (CHB) as the interface with the MV grid, on a modular level a dual active bridge converter (DAB) is connected. Shifting the frequency to medium/high range; these converters provide the required isolation via a smaller transformer, thus a higher power density. Plus, battery energy storage system "BESS" is integrated, acting as a power buffer in low demand time. Via a non-isolated bi-directional buck-boost converter stored energy can either charge the EVs or support the grid. The series input / parallel output modular structure divides the power onto several submodules. Allowing the use of low power rating switches, while providing the power required. To eliminate the circuiting current discussed in (Vasiladiotis \& Rufer, 2015) model predictive control is used to balance the voltage of all submodules, while maintaining the required output voltage. For robust and simple control, a sliding mode controller is applied to control both the DABs and buck-boost converters. A model-based approach is used to calculate sliding mode gains. For, the DAB two models were developed to constant current "CC" and constant voltage "CV" modes, where for both models pole placement method is used to calculate the sliding mode gains
\end{abstract}

Keywords: Bi-directional buck-boost converter; Cascaded H-bridge Converter (CHB); Dual active Bridge Converter (DAB); Model Predictive Control (MPC); Sliding Mode control (SMC). 